CuPAUAM. 15-1988

\title{
EL CERRO DE LOS SANTOS (MONTEALEGRE DEL CASTILLO, ALBACETE): UNA NUEVA INTERPRETACION DEL SANTUARIO
}

\author{
ENCARNACIÓN RUANO RUIZ \\ Asociación Española de \\ Amigos de la Arqueología
}

\section{Resumen}

La reiterada consideración por parte de algunos investigadores sobre el carácter popular y terapéutico del Santuario del Cerro de los Santos, nos ha inducido a presentar como hipótesis de trabajo, la función eminentemente geopolítica y elitista de este Santuario, sin descartar la función curativa.

Los argumentos se basan en el análisis del depósito votivo, en la situación del Santuario y en las distintas categorías de otros lugares de culto.

\section{Summary}

The views often held by some researchers on the popular and therapeutic attributes of the santuary Cerro de los Santos (Montealegre del Castillo, Albacete), has moved us to use it as a working hypothesis, the prominent geopolitical and elitist caracteristic of this sanctuary, without dismissing its atributed healing qualities.

The argument are based on the analitical examination of the offerings place in this sanctuary, and in the different categories of other places of worship.

La reiterada consideración por parte de algunos investigadores sobre el carácter popular y terapéutico del Santuario enclavado en las cercanías de Montealegre del Castillo (M. RUIZ, 1986,$386 ; 1989$, p. 186), nos ha incluido a presentar una nueva hipótesis de trabajo esbozada en nuestra tesis doctoral (E. RUANO, 1987, T. II, 209) - la función eminentemente geopolítica y elitista de este Santuario - sin descartar la posibilidad curativa que se lograba en este centro religioso.

Los argumentos en los que se basa esta hipótesis se deducen de la continuidad de la ofrenda de escultura humana de ambos sexos, desde el inicio del Santuario hasta le época romana, 
la situación territorial y la diversidad de peregrinos y, por último, el contraste con numerosos centros religiosos de más corta duración o de vida larga, pero con otros tipos de exvotos, que permite establecer diferencias con respecto al Cerro de los Santos y postular su carácter focal y posiblemente centralizador.

\section{DEPOSITO VOTIVO}

Las ofrendas que se depositaron en el Santuario responden a dos tipos de exvotos: de piedra y de bronce.

Los exvotos de piedra estudiados representan 392 figuras humanas (E. RUANO, 1987) y 19 animales (Jímenez Navarro, 1942), si a este último grupo, se añade una cabecita de león hasta ahora poco conocida, que fue encontrada por FERNÁNDEZ DE AVILÉS en la excavación de 1962, (Fig. 1.1), once exvotos de bronce, (M. Ruiz, 1989, 163) representan igualmente personajes, (Fig. 1.2).

Somos conscientes de la pérdida de información, por lo que el número total de öfrendas realizadas en el Santuario es susceptible de ser alterado.

\section{I.1. Esculturas Humanas de Piedra}

Hay que puntualizar, para no arrastrar errores, que aunque se estudiaron 392 esculturas, teniendo en cuenta las auténticas y la cabezas cuyos cuerpos fragmentados son difíciles de restituir, las cifras de representaciones individuales alcanzan con seguridad a 93 esculturas femeninas y 124 masculinas; números que pueden ser enriquecidos y, de momento, dan prioridad a la representación del sexo masculino. Todas, salvo la excepción de una pareja, son independientes entre sí, y al igual que las depositadas en el interior de las tumbas o en otros santuarios, no están unidas a elementos arquitectónicos y su formato y configuración, aún en el caso de las piezas de mayor tamaño, permitía su desplazamiento, transporte o movilidad. Es decir su autonomía.

El análisis pormenorizado de las esculturas, el exámen de su indumentaria, peinados, vestidos y joyas, permiten sugerir que los exvotos de este Santuario no reflejan fieles indiscriminados; bien al contrario, en las distintas actitudes y en el atuendo, insisten en personas privilegiadas hombres y mujeres de la élite social.

La figuras femeninas, tanto las completas como las incompletas, exceptuando algunos frag. mentos que representan sólo la parte inferior de las esculturas, muestran la riqueza de su estamento (E. RUANO, 1987, cuadros núms. 1-19). Valgan por ejemplo algunas de estas representacionnes (Fig. 2 y 3).

Las esculturas masculinas, más numerosas, se adornan con torques y pulseras, símbolo de su estatus elevado, como ha demostrado M. L. BANDERA (1988), (E. RUANO, 1987, cuadros núms. 19-46). Son muy escasas las representaciones de guerreros, apenas 5 individuos que llevan cascos o espadas. La fragmentación hace más difícil controlar los signos externos de riqueza (en muchos casos sólo se conserva las cabezas). 


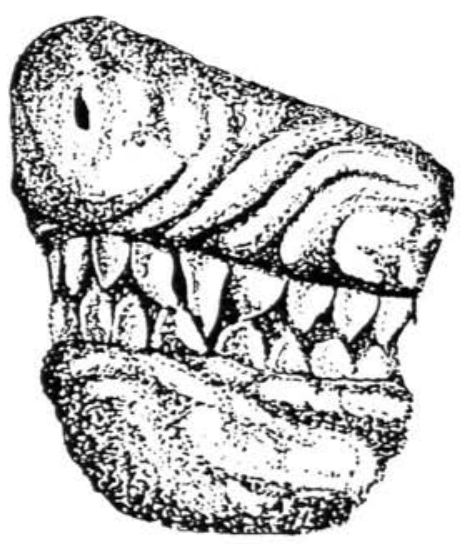

1

2

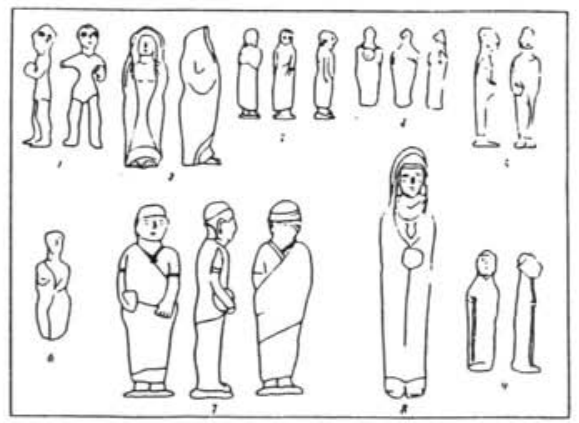

FIG. 1. - 1. Cabecita de león procedente del Cerro de los Santos (Montealegre del Castillo, Albacete); 2. Exvotos de bronce procedentes del Cerro de los Santos (Montealegre del Castillo, Albacete), (M. RUiz, Dib. J. STORCH DE GRACIA). 

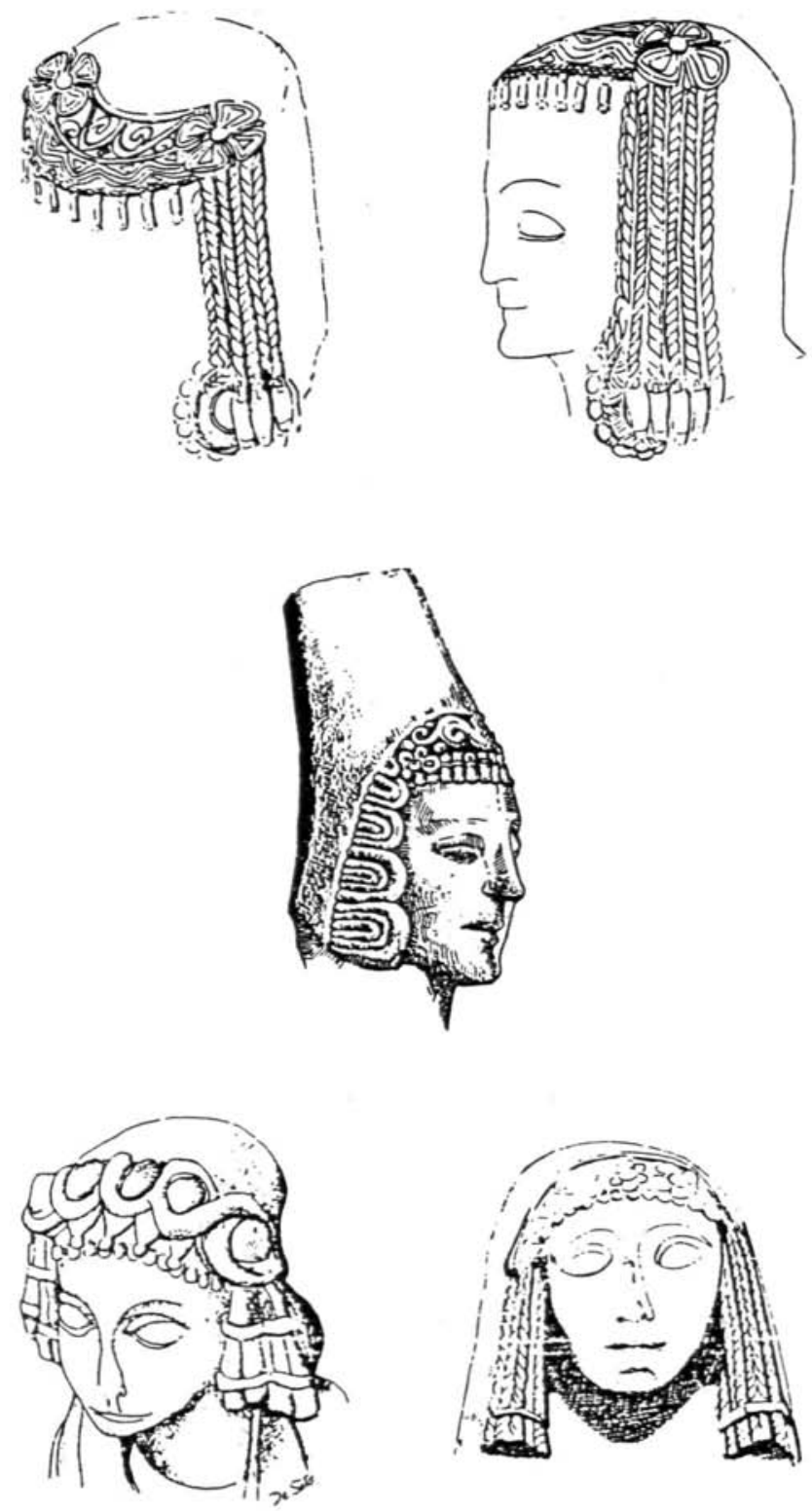

FIG. 2. - Exvotos femeninos procedentes del Santuario del Cerro de los Santos (Montealegre del Castillo, Albacete), (E. RUANO). 

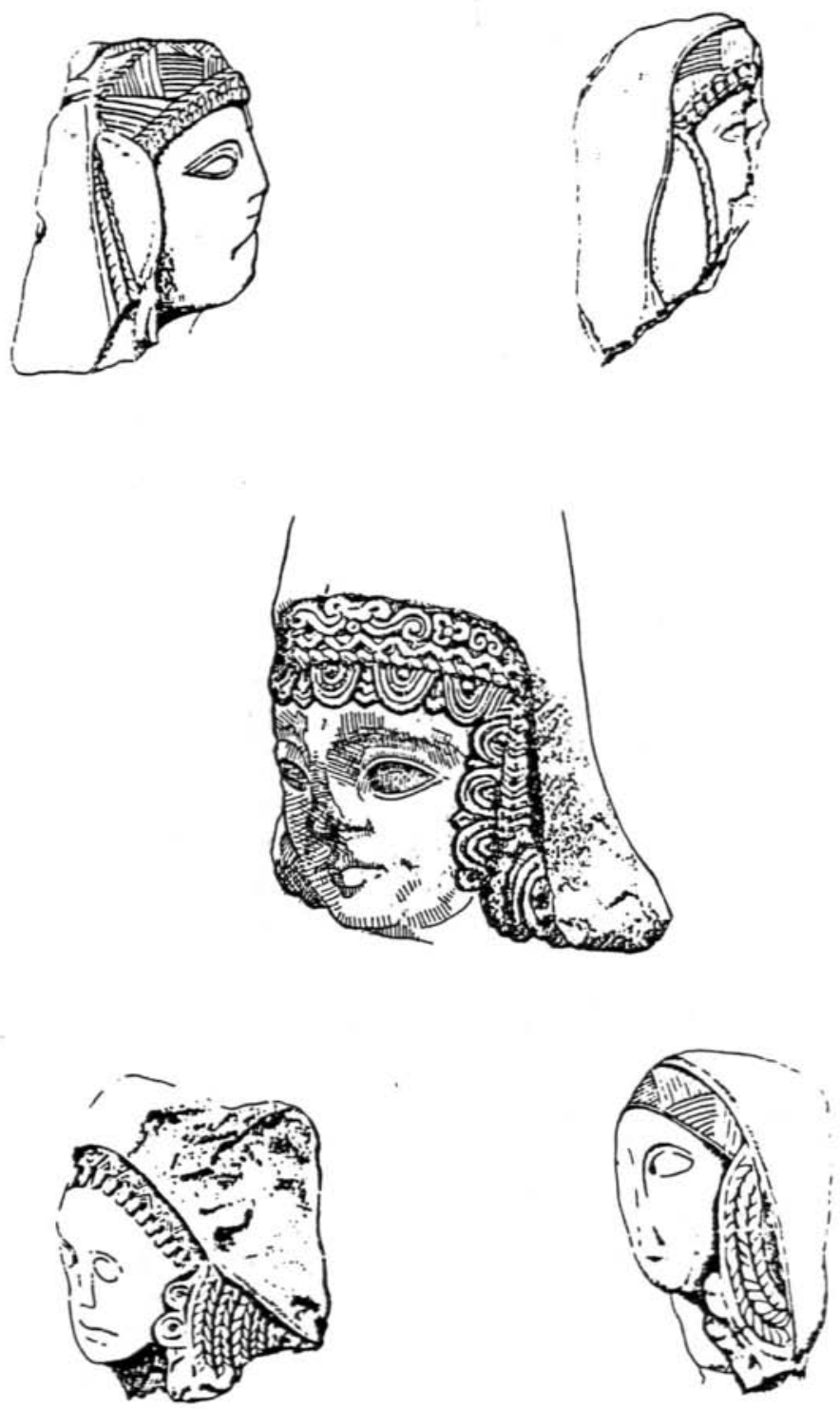

FIG. 3. - Esculturas femeninas procedentes del Cerro de los Santos (Montealegre del Castillo, Albacete), (E. RUANO). 


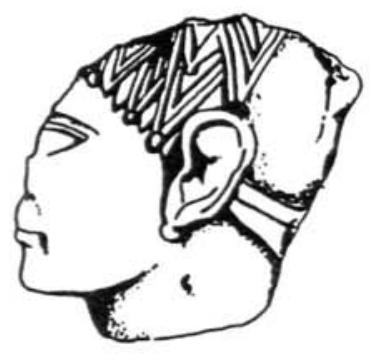

1

3

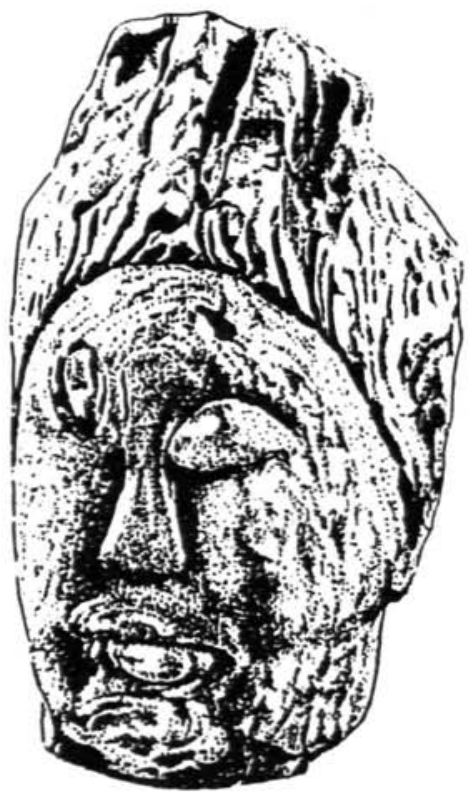

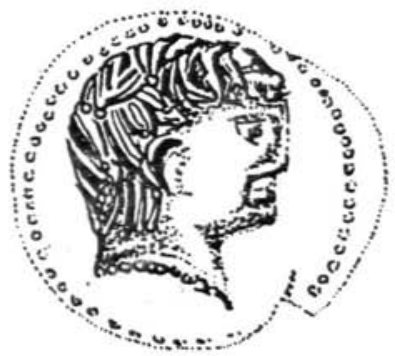

2

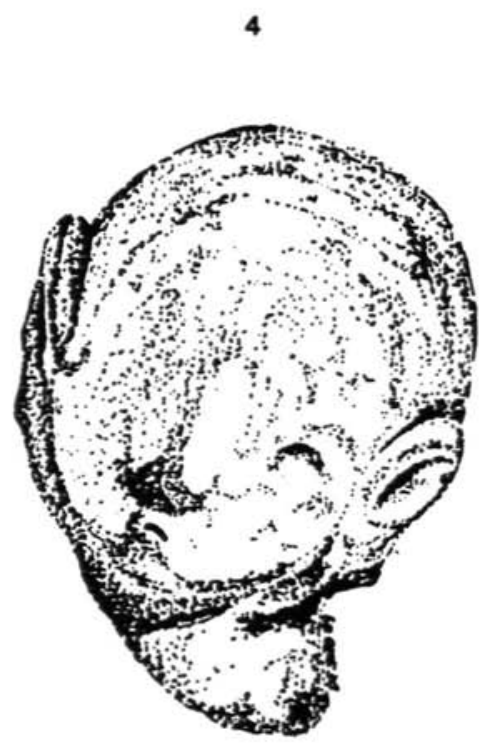

FIG. 4. - 1. Cabeza masculina depositada en el Cerro de los Santos (Montealegre del Castillo, Albacete); 2. Denario acuñado en Ikalosken; 3. Cabeza con mano o garra sobre la cabeza, Cerro de los Santos (Montealegre del Castillo, Albacete); 4. Cabecita procedente del Cerro de los Santos, (Dib. A. Soto). 
En los últimos momentos de la vida del Santuario, las ofrendas de esculturas humanas se hacen todavía más expresivas y acusan la importancia de los fieles que lo visitan. Una cabeza, posible retrato, y los togados que ofrendan la escultura con su propio nombre, Lucio Licinii, el togado que representa a los Bastulanos, según se lee en la inscripción que existe en este tronco.

Gran importancia debió tener en la sociedad ibero-romana el personaje citado que ofreció su efigie (Fig. 4.1). La calidad escultórica de la cabeza - aparece sin atributos- representa a un individuo con un peinado de características singulares, realizado a base de mechones triangulares que inscritos unos en otros, acaban en uno de los vértices con un punto. La escultura que por su realismo aboga por ser un retrato de un personaje civil, presenta principalmente en peinado una gran semejanza con el anverso de un denario de plata de los talleres de "Ikalosken». El reverso de esta moneda presenta un jinete con rodela que lleva otro caballo al lado, supuesto símbolo religioso de los dióscuros (Fig. 4.2).

Las monedas con leyenda «Ikalosken» presentan contravertidas opiniones respecto a la lectura ibérica y a la ubicación de la ceca de emisión, no esclarecidos hasta la actualidad. HeISS leía su leyenda "Ilbrnekn» o "Ilbrekn", y las atribuía a Iliberris en Monte Elvira (Granada); SAULCY lee lo mismo y también las atribuye a Iliberris; ZOBEL lee Igloetes o Iglonenses, a Acci; DELGADO interpreta Ilgone-kn y la atribuia a Ilgone, ciudad de los Iligones; HÜBNER interpreta la leyenda Iclonekn; BOUDARD la localiza en la Ilipa, en la Bética, leyendo Iliponekn.

Modernamente, Pío BELTRÁN lee Igaldon, localizándola en la zona alicantina; GÓMEZ MORENO leía antes Icaloscen y más tarde Icalguscen, con dudas respecto al "gu", atribuyéndolas a Cartagena; MATEU Y LLOPIS sugirió que si el cuarto signo pudiera leerse "tu", cabria pensar en Alicante-Lucentum; ANTONIO BELTRÁN dice Igaldon, Ikaloscen, Ikalguscen y la sitúa en las proximidades de Orke (VILLARONGA, 1962, p. 12). UNTERMANN lee Ikalesken $(1976,217)$.

Con el tiempo los criterios se han unificado y, salvo un par de signos de la leyenda, hay unanimidad en los demás. En cuanto a la localización, como hipotética, se coincide que fueron acuñadas en el sur se España (VILlARONGA, 1962, p. 13).

GÓMEZ MORENO sugiere pudiera estar relacionado con estas monedas el pueblo de Igletes, también citado como Gletes o Ileates, radicados en Andalucía, entre Córdoba y Sevilla, en el valle superior del Betis. También puede relacionarse con Egelasta, nombre de la ciudad cercana a Cástulo y próxima a las minas de plata de Linares y el Centenillo (VILLARONGA, 1962, 24). Es esta Egelasta la que PÉREZ Rojas ha identificado como Yecla, situada a pocos kilómetros del Cerro de los Santos (1). ¿Fue este individuo representado en la moneda contemporánea el que depositó su escultura en el Cerro de los Santos?

(1) Pérez Rojas considera a Egelasta situada en Yecla. Su argumento es el siguiente:

“Según las precisiones de Estrabón sobre el Campus Spartarius (III, 4.9), y los yacimientos de sal medicinal, que no pueden ser más que los de Laguna de la Higuera, pues no existen otros yacimientos con las características cristalográficas descritas por Plinio (XXXI, 80). Esta peculiaridad la hemos constatado en conversación con destacados geólogos. La sal de la Higuera es internacionalmente conocida en el mundo farmacológico, por tratarse de sales de magnesio puras que no requieren tratamiento previo para su utilización. 
La presencia en el Santuario de L. LiCiNI, enriquece la galería de personajes de importancia. El individuo acéfalo viste la "toga exigua" (GARCiA BELLIDO, 1950-1962, 509), semejante a la que muestran otros togados republicanos o palliati (A. BALIL, 1983, 532-533). Con respecto al torso con inscripción, el praenomen de "Lucius Licini» se usó preferentemente en la Bética (CASTILlO GARCiA, 1965, p. 405). El nomen escrito en la escultura y expresado en genitivo, incide a considerarla como una ofrenda o exvoto. En la gens Licinia se encuentran integrados un número considerable de hispano-romanos (RODA DE LLANZA, 107), siendo uno de los nombres más frecuentes en Hispania (A. BALIL, 1965, 363) después de Valerius, Cornelius, Fabius y Aemilius.

No se puede negar que el individuo estaba dotado de la ciudadanía romana y gozaba de cierto estatus económico que le permitió la ofrenda.

La presencia del torso togado, en cuyo pecho se grabó la palabra BASTULAICUN en letra ibérica BASTULAIATIN, según lectura de J. DE HOZ (1976, 257), reafirma la tesis de la ofrenda de los bástulos «alusión epigráfica única de ellos en sentido de oferentes y acreditando la amplitud geográfica de su nombre» (GÓMEZ MORENO, 1961, 879-968). Esta interpretación es admitida por M. LEJEUN y M. FAUST (SILES, 1985, 334).

Los bástulos son los vecinos occidentales de los bastetanos (UNTERMANN, 1985, 23).

ESTRABÓN (III, I, 7) expresa la identidad de bástulos y bastetanos o más probablemente la pertenencia de los primeros a la familia bastetana. Por la costa hace llegar a los bástulos al menos hasta Cádiz (III, 21), situando Calpe (Peñón de Gibraltar) claramente en su territorio (III, I, 7). En la costa entre Calpe y Cartagena "viven la mayoría de los bastetanos, a los que se les suele llamar también bástulos, y una parte de los oretanos" (III, 4, I).

La presencia de los bástulos al oeste del estrecho nos es confirmada por MELA (III, 3) y Plinio (III, 8) (MONTENEGRo et alii, 1989, 322).

El togado republicano o palliatus representa en este caso a cierta comunidad de hispanoromanos que hace su ofrenda en el Cerro de los Santos.

Hemos de hacer constar que no existen ofrendas que representen miembros del cuerpo humano.

\section{I.2. Otras Ofrendas}

Al numeroso grupo de esculturas humanas de piedra, habría que añadir las representaciones de animales; 10 figuras de équidos, 7 bóvidos y 1 cáprido, realizadas en piedras blandas; 19 ejemplares si añadimos la pequeña cabeza de león antes eludida (Fig. 11), cuyas características formales nos lleva a compararla con los leones encontrados en la necrópolis de El Cigarralejo, de muy alta cronologia, pues estaban reutilizadas en tumbas fechadas en el año 375 a. C. (Fig. 5).

Este dato, que inexplicablemente pasó desapercibido, permite identificar Egelasta con absoluta seguridad, hasta el punto de que los profesores R. Marfil, E. P. Bermejo y J. A. de la Peña, del departamento de Petrología de la Facultad de Ciencias Geológicas de la Complutense han aceptado nuestra tesis e incorporan la cita de Plinio en la descripción de estos yacimientos - únicos en occidente - tanto en su ponencia al último Congreso Internacional de Geología, como en un artículo publicado recientemente en Estudios Geológicos, Vol. XXXI, pp. 543-553 CSIC, Madrid». 

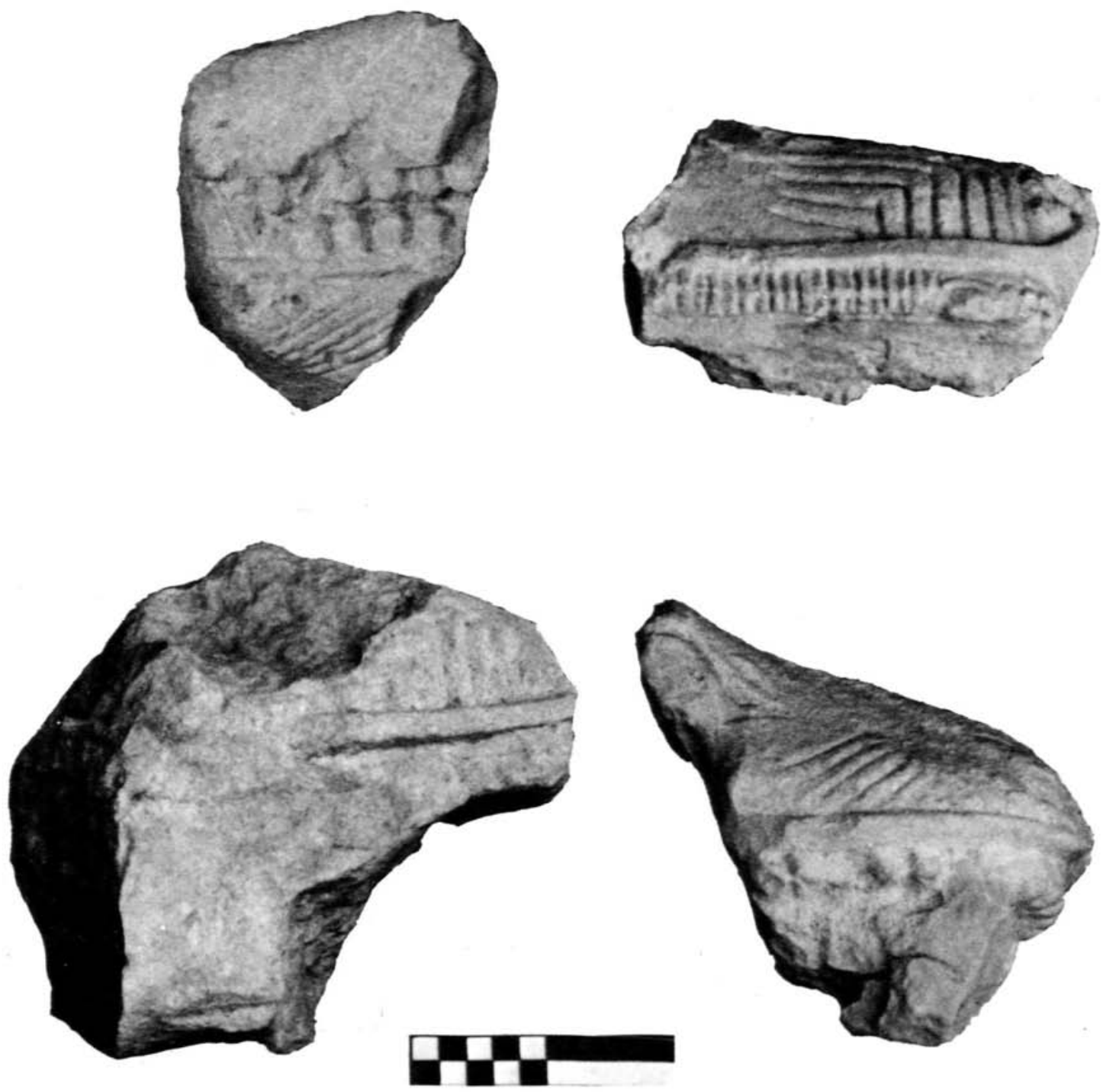

FIG. 5. - Restos escultóricos zoomorfos procedentes de la necrópolis de El Cigarralejo (Mula, Murcia), (Fot. A. Chastell), (cortesía de E. Cuadrado). 
De los 11 exvotos de bronce, sólo 3 proceden con certeza del Santuario. Las figuras representan 9 hombres y 2 mujeres en diversas actitudes ante la divinidad. Tanto el pequeño número de piezas como el análisis pormenorizado de las mismas, lleva a la doctora Ruíz a considerarlas procedentes de santuarios andaluces (Ruíz BREMÓN, 1989, 163 y ss.).

\section{SITUACION DEL SANTUARIO Y PROCEDENCIA DE LOS PEREGRINOS}

El emplazamiento del Santuario está dentro de la vía Heraclea, de antiguo trazado y paso obligado en el trasiego de gentes y mercancías desde el Levante al interior de la península, o en el caminar hacia las tierras andaluzas pasando por Sierra Morena. Esta ruta, cuya relación interregional es un hecho, como el contacto externo evidenciado por los testimonios griegos presentes en el territorio (cerámica, bronces y alfabeto jónico), está jalonada por abundantes restos escultóricos: Játiva, Mogente, Fuente la Higuera, Caudete, Llano de la Consolación, Hoya de Santa Ana, Los Villares, Pozo Moro, Salobral, Balazote, Cástulo.

Desde el punto de vista religioso, la zona de Montealegre del Castillo, goza de una tradicional sacralidad, zona de pinturas rupestres de Monte Arabí y petroglifos (BLÁZQUEZ, PÉREZ ROJAS, 1987, T. I, 206), así como una abundancia en el sitio de aguas o sales con poderes salutíferos. Todas estas concurrencias justifican sobradamente que el lugar se convirtiera en un templo cuya competencia rebasara la del mero santuario adscrito a una simple comunidad rural y se transformara en un centro religioso y político donde jefes de distintas comunidades se reunieran en determinadas ocasiones para realizar sus ofrendas y sancionar acuerdos o alianzas.

Las diferencias entre imágenes afines, tanto de estilo como a sus aditamentos externos o materias en que se realizaron, apuntan por una procedencia distinta de la zona y una captación de fieles que rebasa el marco local. Condensan en el aparato externo todo un muestrario de trajes, tocados, joyas y otros pertrechos cuya materialidad sólo puede relacionarse con la clase "alta" de un amplio sector territorial del mundo ibérico, desde el interior de la meseta (caso de las placas fibula y de algunos tocados) hasta Levante, incluyendo la zona murciana. Ciertas imágenes son afines en estilo o rasgos a otras aparecidos en estas áreas.

La identidad entre el atuendo de las esculturas del santuario y el de la Dama de Elche, nos lleva a ver en ella algún peregrino de esta zona levantina (Fig. 6).

Lo mismo sucedería con la cabecita representada en la Fig. 4.4, con claras semejanzas en las terracotas procedentes del Santuario de la Serreta (Alcoy), (E. RUANO, 1987, T. III).

Hasta el Cerro de los Santos llegaron peregrinos con exvotos desde El Cigarralejo (Mula, Murcia), así parece confirmarlo la cabecita de león (Fig. 1.1) anteriormente citada y el caballito de la Fig. 7.1, que presenta gran semejanza con el procedente del santuario murciano (Fig. 7.2).

Los escasos exvotos de bronce como depósito votivo, 11, ponen en contacto con el santuario a fieles procedentes de Andalucía (RUIZ BREMÓN, 164). 


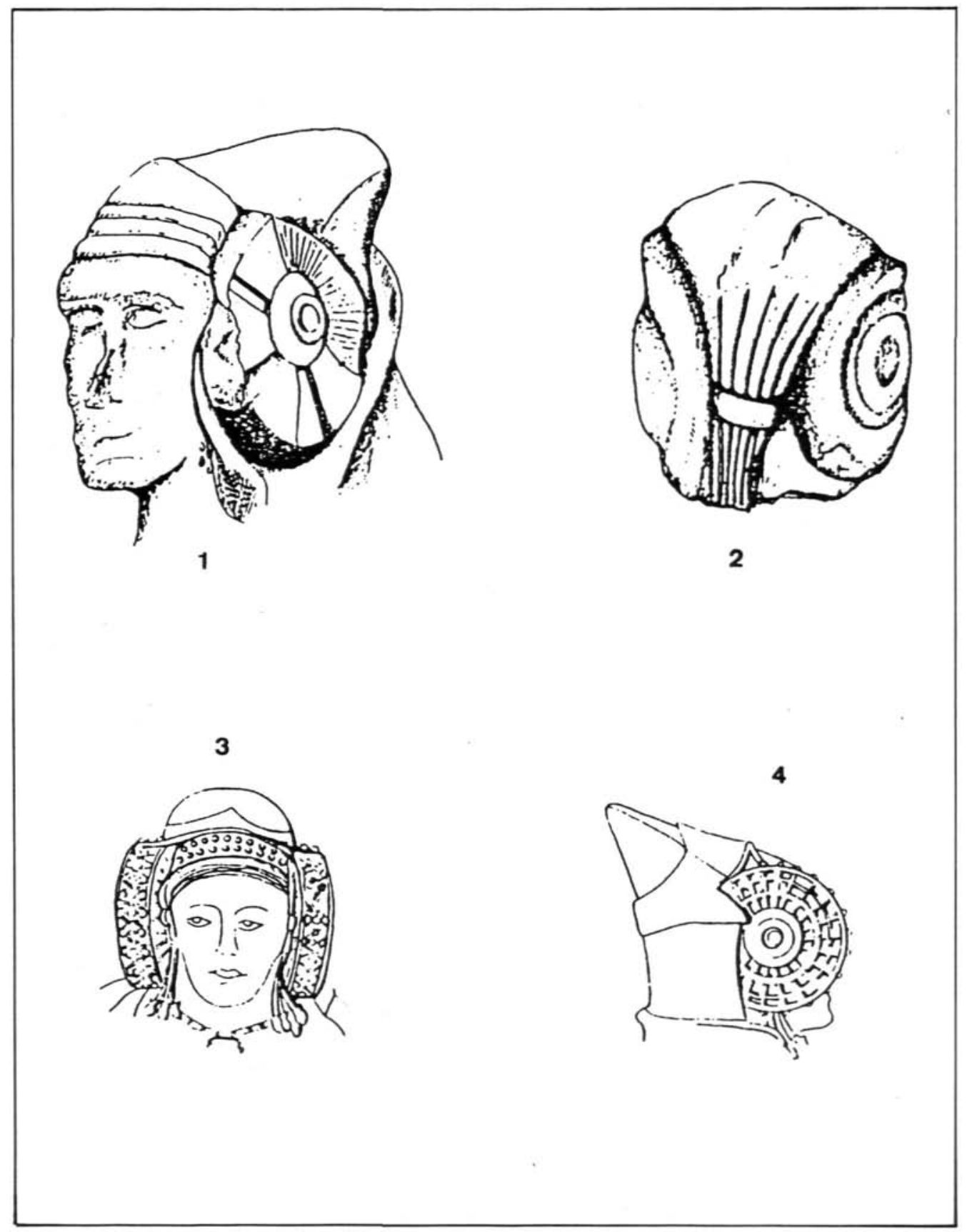

FIG. 6. - 1-2. Cabezas femeninas depositadas en el Cerro de los Santos; 3-4. Dos aspectos diferentes del tocado de la Dama de Elche, (Dib. V. VIÑas). 

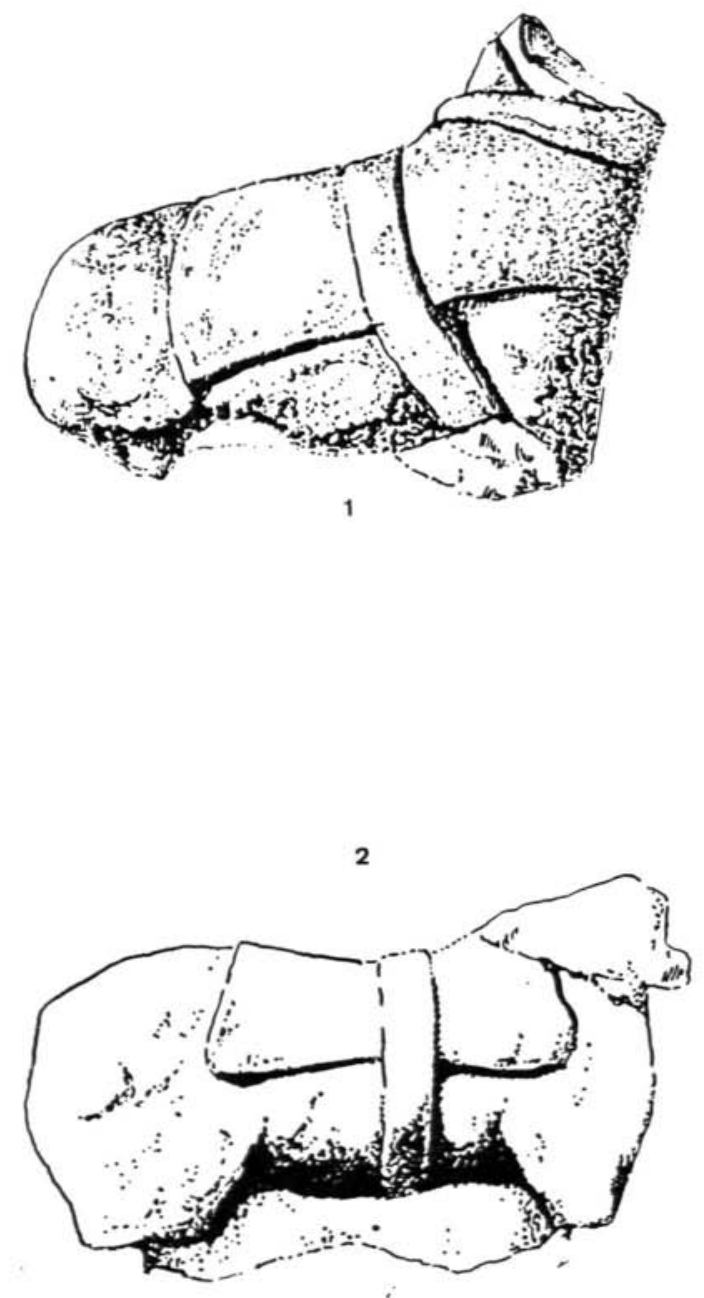

FIG. 7. - 1. Equido procedente del Cerro de los Santos (Montealegre del Castillo, Albacete); 2. Equido procedente de El Cigarralejo (Mula, Murcia). 
A estos datos meramente materiales, debemos de incorporar la existencia en el Cerro del Togado con el nombre de Bastulaiatín, procedente del sur peninsular, posible representación de una gentilidad como antes hemos expuesto.

No debemos olvidar el carácter celta de algunas esculturas (Fig. 4.3), varias cabezas cuyos rasgos presentan paralelos formales con las ofrendas de Santuario de Entremont (BENOIT, 1957). A ello cabe unir que el nombre "Aionicalua", inscrito en el torso femenino, es según considera ALBERTOS, un nombre celta (Siles, 1985, 48).

Entre los exvotos animalistas del Cerro ya distinguió JiMÉNEZ NAVARRO, un grupo con característica de la cultura de los verracos (JIMÉNEZ NAVARRO, 1943, 102). Si tenemos en cuenta sus adornos, también muchas esculturas se relacionan con la meseta. Un guerrero acéfalo armado con una posible espada de antenas.

\section{LUGARES DE CULTO IBERICOS}

Somos conscientes de la dificultad de un estudio de conjunto espacial y cronológico de los lugares de culto ibéricos. Este hecho condiciona notablemente el conocimiento de las distintas categorías de estos centros cultuales y su posible carácter rural-urbano o independiente de un hábitat determinado. Los continuos descubrimientos de depósitos votivos sugieren lugares vinculados o no a la religiosidad de los poblados y contribuyen a incrementar el interés por las excavaciones cuando existen indicios de estructuras cercanas, caso reciente de Torreparedones (Córdoba) (MORENA, 1989).

Intentaremos a continuación dar una aproximación espacial, no cronológica, basada principalmente en las noticias que nos proporcionan los investigadores, incorporando los nuevos hallazgos de exvotos, que suponen por su cantidad un "hecho religioso".

Dentro de los posibles lugares de culto, seguimos la clasificación de R. LUCAS, distinguiendo entre Loca Sacra Libera, depósito de aire libre (DAL) vinculados o no a la religiosidad de los poblados, y en cuevas (C); Santuarios considerando éste como un terreno sagrado en el que se erige algún edificio, ya sea para albergar la estatua de la divinidad o al servicio de determinadas ceremonias o actos relacionados con el culto y la liturgia (S); y Templos, construcciones religiosas de cierta prestancia y carácter urbano, en honor a deidades o personajes que llegan a alcanzar honores divinos (T).

A esta división cabría añadir otro tipo arquitectónico, el palacio-santuario, si consideramos aquí el nuevo edificio encontrado en Zalamea de la Serena (MALUQUER, 1981, 1982, 1983, 1986) (PS).

Siempre que existe duda sobre la ubicación de un lugar de culto se precisa como un interrogante. Hemos de hacer constar la licencia de incluir dentro del mapa dos lugares del interior: la edificación con relieve del Cerrón (Illescas-Toledo), y el edificio anteriormente citado, ubicado en Zalamea de la Serena (Badajoz).

La relación de los posibles lugares de culto es la siguiente (Fig. 7): 


\section{Cataluña}

Gerna. 1. Puig de Sant Andreu (Maktin i ORTEGA, 1977, p. 12) (Tarradell, 1979, p. 37) (T).

Barcelona. 2. Cova Cassimanaya (Begues); 3. Cova de San Sadurní (Begues); 4. Cova avenc Gegant (Sitges); 5. Cova del Bolet (San Quinti de Mediona), (VEGA, J. 1987, pp. 177-188); 6. Mont Aguilar (Badalona), (Tarradell, 1979, p. 39).

Tarragona. 6 bis. Cova de l'Oila o del Sumá (Marmellar); 7. Cova de Garrofet (Celma, Querol); 8. Cova de la Font Mayor (L'Espluga de Francolí), (VEGA, J. 1987, pp. 177-188); 9. LAreny (Mont-Roig), (Tarradell, 1979, p. 40).

Lérida. 9 bis. Cova Colomera o de los Gralles (Alçamora, San Esteve de la Sarga), (VEGA, J., 1987, pp. 177-188).

\section{Aragón}

Zaragoza. 10. Azaila (CABré, J., 1925, p. 300), (Beltrán Lloris, 1976, p. 427), (2), (T).

\section{Comunidad de Valencia}

Castellón. 11. Santa Bárbara (Vilavella de Nules), (Vicent y CaVAlLer, 1979).

Valencia. 12. Cova del Cavall (Olocau); 13. Coveta dels Sant (Alcudia de Crespins); 14. Cova de les Dones (Millares); 15. Sima del'Aigua (Carcagente); 16. Cueva Santa (Enguera); 17. Cueva de los Angeles (Requena) (APARICIO, 1976, pp. 12-19); 18. Cova de les Mirevelles (Gandía); 19. Sima de l'Infern de Tous; 20. Cueva del Cerro Hueco de Requena (TARRA. DELL, 1973, p. 29-32); 21. Muntanya Frontera (Sagunto), (TARRADELL, 1979, p. 44); 22. Villagordo del Cabriel (GIL MasCarell, 1977), (S). 1.

Alicante. 23. La Escuera (San Fulgencio), (ABAD, 1986, pp. 146-147), (T); 24. La Serreta (Alcoy), (VISEDO, 1921-1922), (JUAN MOLTÓ, 1987-1988, pp. 295-329); 25. Illeta de Banyests (Campello), (Llobregat CONESA, 1986-1988); 26. Cueva del término de Ondara (TA. RRADELL, 1973, p. 34); 27. Cueva de la Pinta (Callosa d'Ensarriá), (APARICIO, 1976, p. 18); 28. Castillo de Guardamar (ABAD, 1986, pp. 151-152), (3), (T); 29. Tossal de Polop o de la Cala (Benidorm), (Llobregat CONESA, 1972, pp. 60-62), (S)?

\section{Comunidad de Murcia}

Coimbra de Barranco Ancho (Jumilla) (GARCíA CANO et alii, 1987, p. 669) (S); 31. Recuesto (Cehegín), (Lillo, 1981) (S); 32. El Cigarralejo (Mula), (CuAdRado, 1950) (S); 33. La Luz (Santa Catalina del Monte), (Ruíz BREMón, 1988, pp. 230-244) (S); 34. La Encarnación (Caravaca), (E. RUANO y SAN NiCOLÁs, en prensa) (DAL); 35. Cuevas del Calor (Cehegín); 36. Las Canteras (Calasparra); 37. Peliciego (Jumilla); 38. La Naríz (Umbría de Salchite, Moratalla); 39. Peña Rubia (Cehegín); 40. Poyo Miñano (LILlo, 1981, pp. 41-45).

(2) "Edificio cúltico" posible.

(3) “Parece más lógico, por tanto, pensar que nos encontramos ante un santuario, situado en el lugar más destacado del entorno y que debía aglutinar a los habitantes de los numerosos poblados ibéricos de la desembocadura del Segura, alguno de los cuales (Cabezo Lucero, La Escuera, El Oral), están siendo objeto de excavaciones en la actualidad». 


\section{Andalucía}

Jaén. 41. Castellar de Santisteban (Los Altos del Sotillo), R. LANTIER, J. CaBré (S), 42. Collado de los Jardines (Santa Elena), (L. Calvo y J. CaBRÉ, 1918) (S); 43. Torre de Benzalá (Torredonjimeno), (E. RUANO, 1987, T. I) (DAL); 44. Cástulo (Linares), BLÁZQUEZ, 1981, 202); 45. Cástulo (Linares), (LuCAS PELlices y E. RuANO, en prensa) (T) (?)

Córdoba. 46. Mesa de Luque (CUADRADO, E. RUANO, 1989) (DAL); 47. Torreparedones (MORENA, 1989) (S); 47 bis. Cueva de la Murcielaguina (Priego) (VAQUERIZO, 1985, 115).

Granada. 48. Cerro de los Infantes (Pinos Puente), (Rodríguez Oliva et alii) (DAL).

\section{Castilla-La Mancha}

Ciudad Real. 49. Alarcos (Caballero Klink, Mena MuÑoz, 1987, pp. 615-634) (S). Toledo. 50. El Cerrón (Illescas), (L. S. BAlsamedA, S. VAliente, 1979 y 1981).

\section{Extremadura}

Badajoz. 51. Cancho Roano (Zalamea la Serena), (MALUQUER DE MOTES, 1981, 1. 1983, 1986) (PS).

De esta distribución espacial se pueden sacar algunas conclusiones:

1. Destacar la importancia que alcanzó el culto en cuevas como demuestran las múltiples cavidades sagradas en Murcia, Valencia y Cataluña.

2. La concentración en Murcia de santuarios cercanos a poblados; El Cigarralejo (Mula), Recuesto (Cehegín), Encarnación, Los Villares (Caravaca), La Luz (Santa Catalina del Monte).

3. La importancia en Andalucía de dos santuarios jienenses: Castellar de Santisteban y Collado de los Jardines.

4. La existencia de edificios cultuales de prestigio; Illeta de Banyets.

5. La aparición de una edificación con un carácter nuevo; el Santuario-palacio de Zalamea la Serena.

Las lagunas en la información sólo permiten ratificar que los santuarios ibéricos debieron ser numerosos y cada uno gozó de una especificidad particularizada y, por lo conocido, la estatuaria en piedra de buena factura, fue siempre excepcional.

Los argumentos anteriormente expuestos se ven en cierta manera reforzados por algunas de las conclusiones recogidas en la tesis del doctor PÉREZ ROJAS, basadas en estudios lingüísticos (1978).

- Los pueblos ibéricos están organizados en pentápolis y la hipótesis de este tipo de organización se deduce de la lectura de los epígrafes procedentes de Mogente, Ampurias, Orleyl I y Gador. 


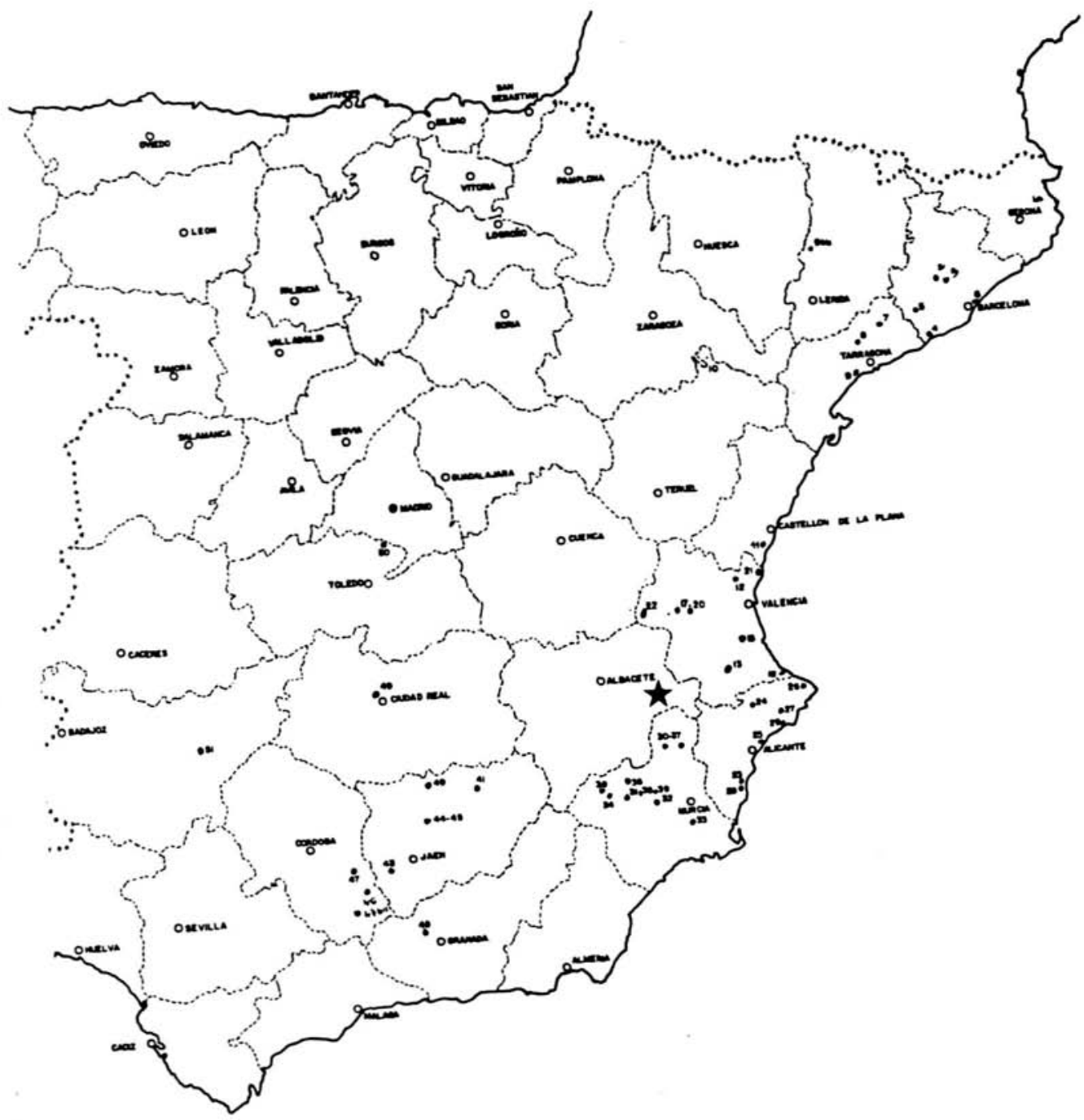

FIG. 8. - Mapa con la situación de los santuarios y posibles lugares de culto indígena. 
- El Cerro de los Santos se sitúa en el centro de dos pentápolis cuyo territorio se conoce por el aludido plomo de Mogente.

- Según las fuentes escritas la comarca de Ayora, que cierra la cuenca del Júcar, constituye una elevación «sobre las estatuas» (Traducción de OUR-ILDER). Este dato apunta al santuario como punto de referencia en cuyo caso, si la traducción es correcta, existe la posibilidad de que las esculturas estuvieran al aire libre.

El planteamiento hipotético del Cerro entre dos pentápolis que hace PÉREZ ROJAS, convierte efectivamente el lugar en un punto focal, equidistante y en conjunción con una supraorganización territorial, y en tal sentido el santuario podría funcionar como punto de encuentro para sacralizar vínculos entre diversas comunidades ibéricas, honrando a sus caudillos o representantes más dignos.

La inscripción hallada en Vilar de Perdices al Noroeste de Chaves, Portugal, sirve de ejemplo para comprobar la costumbre de ratificar pactos en los templos (BLÁZQUEZ, 1981, p. 202) (4).

Las violentas o intencionadas destrucciones y mutilación de estas figuras (especialmente de las masculinas), el respeto a las imágenes divinas, la presencia de los togados y de personajes individualizados con su propio nombre o la alusión a su gentilidad, abonan esta idea de las connotaciones políticas y de que el lugar servía para honrar y exaltar públicamente a unos pocos miembros de la aristocracia o a los propios régulos y caudillos que regían el gobierno de comunidades de distinta filiación.

\section{CONCLUSIONES}

A través de las ofrendas, tanto de piedra como de bronces, que permiten considerarse como un medio de comunicación que trasciende a lo racional y se inserta en lo simbólico, se puede traslucir información no estrictamente religiosa, sino social y política. Esto es, en nuestra opinión, el caso del Cerro de los Santos. Su depósito escultórico e identidad de las representaciones, justifican la importancia estratégica, económica, política y religiosa de este lugar. Fue visitado durante más de 300 años por gentes nobles, de distintos ámbitos y usado

(4) La inscripción Villar de Perdices, al Noroeste de Chaves, Portugal, dice: "Callius Reburro foco deva (um) divo (umque) icen (icum) in ac (ta) conducta conservada / sois in ac (ta) conducta P (ublis) Mici (ius) au (ctor) $\mathrm{N}$ (unimum) eis / nucupaverit si r (es) p (ublicae) vaecu (um) nova res (publica) ae (de) me/a sis sil (ice) sipuir ea res (publica) ae (de) me/a sis sil (ice) sipuit ea res (publica) v (otum) S (olverunt) I (ibenter) v (olentes) lanceroi, que Colmenero traduce: Calio, hijo de Reburro, presente ante el altar de las diosas y dioses Icémicos con el fin de renovar para los suyos los pactos llevados a cabo anteriormente para lo mismo Publio Micio, garante de los númenes quien les habia declarado solemnemente: de este modo, república de los vaecos, a una nueva república asociada a mi santuario. Esta república selló el pacto sobre la roca. Ofrecieron su voto con ánimo complacido los lanceroi». Se refiere, pues, la inscripción a un pacto efectuado con anterioridad, por los pueblos de los vaecoi y de los lanceroi ante el altar o santuario de los dioses icémicos. Se desconoce la naturaleza del pacto pero queda claro que su obligatoriedad responde a vínculos religiosos. Los acuerdos los renuevan Calio Reburro y Publio Micio. Había en este paraje un santuario dedicado a los dioses y diosas icémicos, que quizá sea la citada roca. Los dioses son probablemente de naturaleza gentilicia. El carácter de los dioses es desconocido pero posiblemente son de carácter infernal, que eran los que sellaban estos pactos comúnmente. 
como punto focal. Alli podrian ratificarse pactos, acuerdos, matrimonios o alianzas, vinculado a varias comunidades. Es decir, un santuario de interés geopolítico. Todo ello coincidiendo con el inicio de la romanidad se acusa cierto trasfondo continental propio del sincretismo religioso; algún ligero matiz celta que no sabemos hasta qué punto despierta viejas raíces o testimonia esporádicamente la presencia de otros usuarios en el santuario. Sea cual fuere la explicación, el fenómeno traduce las vicisitudes históricas. 


\section{Bibliografia}

ABAD, L. (1986): "Castillo de Guardamar", Arqueologia de Alicante, 1976-1986, pp. 151-152.

ABAD, L. (1986): "La Escuera, San Fulgencio», Arqueologia de Alicante, 1976-1986.

APARICIO PÉREZ, J. L. (1986): «El culto en cuevas de la región valencian». Homenaje a García Bellido, RUM, Vol. XXV, pp. 90-130.

BALIL, A. (1965): "Riqueza y sociedad en la España Romana, siglo III-I a. C.”, Hispania, 99, pp. $325-366$.

BALIL, A. (1983): «Esculturas romanas de la península ibérica», Studia Archologica, 73.

BALSAMEDA, L. S.; VAliente, S. (1979): «Excavaciones en el Cerrón (Illescas-Toledo)», NAH, 7, pp. 153-210, Madrid.

Balsameda, L. S.; Valiente, S. (1981): «El relieve de Illescas», AEA, Vol. 54, pp. 215-238.

Beltrán Lloris, M. (1976): Arqueología e Historia de las ciudades antiguas del Cabezo de Alcalá de Azaila (Teruel), Zaragoza.

BANDERA Romero, M. L. (1988): «Estudio crítico de los torques ibéricos", Habis, 18-19.

Blázquez, J. M.a ; Valiente, J. (1981): Cástulo III, EAE, 117.

BLÁZQUEZ, J. M. ${ }^{a}$ (1981): «El sincretismo en la Hispania Romana entre las religiones indígenas, griega, romana, fenicia y mistéricas». La religión romana en Hispania. Symposio organizado por el Instituto de Arqueología Rodrigo Caro, CSIC, del 17 al 19 de diciembre de 1979.

Caballero Klink, A.; Mena Muñoz, P. (1987): "Los exvotos ibéricos del oppidum de Alarcos", XVIII CNA, Islas Canarias, 1985, pp. 615-634, Zaragoza.

CABRE, J. (1925): «Los bronces de Azaila», AEAA, T. I. pp. 297-315. Madrid.

CAlvo, L.; CABRE, J. (1918): «Excavaciones en la cueva y Collado de los Jardines", M y SEA.

CASTillo García, C. (1965): "Prosopographia Baetica», Universidad de Navarra, Pamplona.

CuAdrado Díaz, E. (1950): "Excavaciones en el Santuario Ibérico de El Cigarralejo, Mula (Murcia)", IM, 21, Madrid.

CuAdrado Díaz, E.; Ruano Ruiz, E. (1989): Esculturas de équidos de la colección Alhonoz, Puente Genil (Córdoba), TP, 46.

García Cano, J. M.; Iniesta San Martin, A.; Molina García, J.; Page del Pozo, V. (1987): «Vasitos de madera de la necrópolis ibérica de "El Poblado" de Coimbra de Barranco Ancho (JumillaMurcia)", XVIII CNA, 1985, pp. 669-680, Islas Canarias.

Gil Mascarell, M. (1975): «Sobre las cuevas ibéricas del País Valenciano, Materiales y problemas". Papeles del Laboratorio de Arqueologia de Valencia, 11, L Aniversario de la Fundación del Laboratorio de Arqueología, 1924-1974.

Gil MASCARell, M. (1977): "Excavaciones en la cueva ritual de Villargordo del Cabriel (Valencia)", XIV CNA, Vitoria, 1975, pp. 705-710, Zaragoza.

GARCIA BELLIDO, A. (1950): "Dos datos cronológicos relativos a la escultura y la epigrafía ibéricas", Estudios dedicados a Menéndez Pidal, 1-2, pp. 506-514.

GÓMEZ MORENO, M. (1961): «La escritura bastulo-turdetana». RABM, LXIX, pp. 879-968.

HoZ, J. (1976): «La epigrafía prelatina, meridional en Hispania». Actas del Primer Coloquio sobre lenguas y culturas prerromanas de la Península Ibérica, 1974, pp. 227-319. Salamanca.

JimÉNEZ NAVARRO, E. (1943): «Figuras animalistas del Cerro de los Santos, Ampurias V, pp. 95-108.

JuAn i Molto, J. (1987): "El conjunt de terracotes votives del Santuari de la Serreta", Saguntum 2. pp. 295-329, Valencia.

LANTIER, R.; CABRE, J. (1917): «El santuario ibérico de Castellar de Santisteban, Com. Inv. Pal. y Preh., Madrid. 
LILlo CARPIO, P. (1983): «Una aportación al estudio de la religión ibérica». La diosa de los lobos de la Umbría de Salchite (Moratalla)», XVI CNA. Murcia-Catagena, 1982, pp. 769 y ss., Zaragoza.

Lillo CARPIO, P. (1981): «Las religiones indigenas de la Hispania Antigua en el Sureste Peninsular. Un nuevo lugar de culto ibérico. "El Recuesto", Cehegín, Murcia”. Anales de la Universidad de Murcia, XXXIX, curso 1981-1981, pp. 195-208.

LuCAS Pellicer, M. R. (1981): "Santuario y dioses en la baja época ibérica», Actas de la AEAA, pp. 232 y ss.

Lucas Pellicer, M. R.; RuAno Ruiz, E.: «Sobre la arquitectura ibérica de Cástulo. Reconstrucción de una fachada monumental", AEA, 1990 (en prensa).

Llobregat Conesa, E. A. (1988): “Illeta dels Banyets, Campello (Alicante)", Memóries Arqueologiques en la comunitat valenciana, 1984-1985, pp. 73-78.

Llobregat Conesa, E. A.; García Hernández, F. (1986): "Illeta dels Banyets, Campello (Alicante", Arqueologia en Alicante, 1976-1986, pp. 63-67, Alicante.

Llobregat Conesa, E. A. (1971): Contestania Ibérica, Instituto de Estudios Alicantinos, Serie II-2, Alicante.

MALUQUeR DE MOTES, J. (1981): «El santuario protohistórico de Zalamea de la Serena, Badajoz I, 1978-1981". Departamento de Prehistoria y Arqueología de la Universidad de Barcelona.

MAluQuer De MOTES, J. (1982): «Note sur un Palais-Santuarie protohistorique á Zalamea de la Serena (Badajoz). Revista de Ouest et du Centre Ouest», Hommage a J. J. Halt, 1981-1982.

MaluQuer De MOTES, J. (1983): El santuario protohistórico de Zalamea de la Serena, Badajoz II, 1981-1982, Departamento de Prehistoria y Arqueología de la Universidad de Barcelona.

MaluQuer De Motes, J.; Destino, S.; Gracia, F.; Munilla, G. (1986): El santuario protohistórico de Zalamea de la Serena. Badajoz III, 1983-1986. Departamento de Prehistoria y Arqueología de la Universidad de Barcelona, 281 pp.

MARTIN I ORTEGA, A. (1977): Ullastret, poblat iberi, Gerona.

montenegro, A.; Blázquez, J. M.; Ruiz Mata, D.; García Cano, J. M.; Iniesta, A.; Fatas, G.; SAlinas, M.; PASTOR, M. (1989): Los pueblos prerromanos, H. ${ }^{a}$ de España 2.

MORENA LÓPEZ, J. A. (1989): «El santuario ibérico de Torreparedones, Castro del Río-Baena, Córdoba.

PÉrez Rojas, M. (1978) Inédito: «Estudio estructural de las instituciones civiles a través de la epigrafía hispánica (Tesis doctoral inédita. Agradecemos al autor las facilidades para su lectura).

Roda de Llanza, I. (1970): Lucius Licinius Secundus, liberto de Lucius Licinius Suran, Pyrenae VI, Pp. 167 y ss.

Rodriguez Oliva, P.; Peregrinn Pardo, F.; Auderica Frias, J. R. (1983): «Exvotos ibéricos con relieves de équidos en la Vega Granadina», XVI CNA, Murcia-Cartagena, 1982, Zaragoza, pp. 751-768.

RuANO Ruiz, E.; 1987. La escultura humana de piedra en el mundo ibérico, 3 vols. Madrid.

RuANo Ruiz, E.; SAN Nicolás, M.: «Exvotos ibéricos procedentes de la Encarnación (CaravacaMurcia). Homenaje a E. Cuadrado (en prensa).

Ruiz BREMÓN, M. (1988): «Aproximación al estudio del santuario ibérico de la Luz». AEA 157-158, vol. 61 , pp. $230-244$.

RUIZ BREMÓN, M. (1985): “El Cerro de los Santos y su interpretación religiosa», I Congreso de Historia de Castilla-La Mancha, pp. 385-390, Ciudad Real.

Ruiz Bremón, M. (1989): Los exvotos del Santuario ibérico del Cerro de los Santos, Instituto de Estudio Albacetenses en la Excma. Diputación Provincial de Albacete, CSIC, Confederación Española de Centros de Estudios Locales, serie I, Ensayos Históricos y Científicos, 40, p. 291, Albacete.

SILES (1985): Epigrafia Hispánica. Léxico de Inscripciones ibéricas, Madrid.

TARRADEll MATEU, M. (1979): «Santuaris ibérics ibero-romans a llocs alts». Memoria del Instituto de Arqueología y Prehistoria de la Universidad ce Barcelona.

TARRADell MATEU, M. (1973): "Cuevas sagradas o cuevas santuarios, un aspecto poco valorado de la religión ibérica». Memoria del Insituto de Arqueología y Prehistoria de la Universidad de Barcelona, pp. 25-39. 
UNTERmanN, J. (1976): "Las leyendas monetales». Actas del I Coloquio sobre lengua y culturas prerromanas de la Península Ibérica, 1974, Salamanca.

UNTERMANN, J. (1985): "El suroeste hispánico en el época prerromana». De Tartessos a Cervantes, Ed. Wenzlaff-Eggebert.

VAQUeRIzo, O. (1985): La cueva de la Murcielaguina en Priego-Córdoba, una posible cueva santuario ibérica.

VEGA, J. A.: "Contribución catalana a l'inventari de les probables coves-santuari iberiques". Fonaments 6, pp. 171-193.

ViCENTE I CARVAller, J. «Excavaciones al Santuari Hispano-Romá de Santa Bárbara, Vilavélla de Nules, Valencia, Plana Baixa". Cuadernos de Prehistoria y Arqueologia Castellonenses, 6. Diputación Provincial de Castellón de la Plana.

VILlarongA, L. (1988): "Els denaris ibérics d'Ikalkusken". Estudis Numismátics Valencians, 3, Valencia.

VILlARONGA, L. (1962): Los denarios con leyenda Icalgusken, Asociación Numismática Española.

VISEDO, C. (1921-1922): «Excavaciones en el Monte de la Serreta, próximo a Alcoy (Alicante), M J SEA, 41 y 42. 